\title{
DIRECTIONS FOR USE OF THE TABLE.
}

The column M contains multipliers, one of which, properly selected, will always bring the natural number to be dealt with within the limits $10,000,000$ and $10,800,000$. The column $\log \frac{1}{\mathbf{M}}$ contains the log., to 10 places, of the reciprocals of those multipliers.

To find the log. to eight places of any number over $10,800,000$. Take the multiplier corresponding to the first three figures of the number in the column $\mathrm{N}$, , or to the next lower if those figures are not found there. Multiply by it the number to be dealt with. Find the log. of the result from one of the tables referred to. Add to that $\log$. the $\log \frac{1}{M}$ from this table. The sum, properly reduced to eight places, gives the log. required.

To find the natural number to eight places of any log. over $033 \ldots$ Add thereto the $\log \frac{1}{M}$ corresponding to the first three places of the log. in the above table, or, if not found there, to the next lower places there found. The resulting log. will be between .00000000 and 03300000 . Find its natural number, which is then to be multiplied by the corresponding $M$. The product is the natural number sought.

It will make the result in all cases rather more accurate if 25 in the ninth and tenth places be added to the tabular log. where the last figure has not been inereased, and subtraeted where it has been increased in those tables which give information on that point.

\section{PREMIUMS FOR CONTINGENT ASSURANCES.}

To the Editor of the Journat of the Institute of Actuaries.

SIr,-I have read with interest Mr. Chatham's letter which appears in the last number of the Journal (see J.I.A., xxv, 489). For some time I have thought it wonld be desirable to tabulate corrections, such as those which he gives on pp 441 and 442 , by means of which the premium for assuring $x$ against $y$ and for $t$ years longer might be easily deduced from the premium for assuring $x$ against $y$.

It appears to me, however, not unlikely that the $\mathrm{H}^{\mathrm{M}} \mathrm{Table}$, which by some of the best authorities is held inapplicable to the ealculation of premiums generally, may, on examination, prove specially inappropriate for quoting rates for contingent assurances. 
Contingent assurances, as we know, are generally effected to cover loans advanced upon reversions in cases where the reversioner must survive the life-tenant in order to acquire a vested interest. The persons on whose lives these assurances are effected are probably somewhat under the average in point of vitality, being, many of them impecunious and some of them dissipated; the life-tenants of the trust estates on the other hand are generally in comfortable circumstances, and I believe considerably more than half of them are women, and their vitality will therefore probably exceed that of the $\mathrm{H}^{\mathrm{M}}$ Table. It is of great importance not to under-estimate the risk attaching to these assurances, since they are effected in great numbers and often for very large amounts.

The exact calculation of a table of contingent insurance premiums, in which the lives insured follow one table of mortality and the lives insured against another, and in which also the effect of selection in each case is duly taken account of, is one of some difficulty. On this point I have been making some experiments, in order to frame a set of premiums for the use of my own office, and give you in the annexed table some of the results which $I$ hare obtained, reserving for a future letter an explanation of the processes employed. The mortality tables employed in the calculation of these rates are-(1) for the lives assured, Mr. Sprague's Select Mortality Tables, given pp 398, 399 , of Vol, xxii of the Journal, with this modification, practically unimportant, that the column $l_{[x-4]+4}$ has been omitted and its place supplied by the column $l_{x} ;(2)$ for the lives assured against, Mr. Finlaison's Female Government Annuitants' Analyzed Table of 1884.

It will be noticed that the premiums of my table, as a rule, exceed those given by Mr. Chatham on pp 442 and 443 , based on the $\mathrm{H}^{\mathrm{M}}$ Table, the difference in some cases being very considerable. Take, for instance, the ease of 20 against 60 . The single premium given below is 45 per-cent higher than the $\mathrm{H}^{\mathrm{M}}$ \& per-cent single premium, and the annual premium is over 31 per-cent higher than the $\mathbf{H}^{\mathrm{M}} 4$ per-cent annual preminm.

$$
\begin{aligned}
& \text { I am, Sir, } \\
& \text { Your obedient servant, }
\end{aligned}
$$

\section{A. W. 'SUNDERILAND.}

National Life Asurance Society,

2, King William Street, London, 30 June 1880. 
Table of Single and Annual Premiums for Insuring $x$ against $y$, the Mortality Table for $x$ being Sprague's Select Mortality Tables (modified), for y Finlaison's Female Government Annuitants' Analyzed Tabì , 1884. Interest 4 per-cent.

Table of $\mathrm{A}_{[x][y]}^{\mathbf{1}}$.

\begin{tabular}{|c|c|c|c|c|c|}
\hline $\begin{array}{l}x \\
\text { II }\end{array}$ & $y=40$ & $y=\mathbf{5 0}$ & $y=60$ & $y=70$ & $y=\mathbf{8 0}$ \\
\hline 20 & $\cdot 15322$ & $\cdot 12687$ & .09902 & $\cdot 06962$ & $\cdot 04486$ \\
\hline 30 & $\cdot 18574$ & $\cdot 14689$ & $\cdot 10704$ & .06961 & .04168 \\
\hline 40 & $\ldots$ & $\cdot 20097$ & $\cdot 14969$ & .09286 & .05286 \\
\hline 50 & $\ldots$ & $\ldots$ & -23843 & $\cdot 14906$ & -08332 \\
\hline 60 & $\ldots$ & $\ldots$ & $\ldots$ & $\cdot 26462$ & -15656 \\
\hline
\end{tabular}

Table of $\varpi_{[x][y]}^{1}$.

\begin{tabular}{|c|c|c|c|c|c|}
\hline $\begin{array}{l}x \\
\| 1\end{array}$ & $y=40$ & $y=50$ & $y=60$ & $y=70$ & $y=80$ \\
\hline 20 & .010244 & 009537 & .009016 & .008591 & .008066 \\
\hline 30 & $\cdot 012663$ & .011145 & .009765 & .008573 & .007473 \\
\hline 40 & ... & .016685 & .014050 & .011609 & .009543 \\
\hline 50 & $\ldots$ & ... & .023947 & -019380 & -015344 \\
\hline 60 & $\ldots$ & $\ldots$ & $\ldots$ & .037767 & 030868 \\
\hline
\end{tabular}

